\title{
Quantitative measurement of bioactive compounds from leaves of Syzygium samarangense with antioxidant efficacy
}

\author{
Rajib Majumder ${ }^{1}$, Md. Badrul Alam ${ }^{2}$, Sayeeda Tasneem Chowdhury ${ }^{3}$, Vivek K. Bajpai ${ }^{4 *}$ and Shruti \\ Shukla ${ }^{5}$ \\ ${ }^{\prime}$ Department of Biological Sciences, Macquarie University, Sydney, NSW 2109, Australia. \\ ${ }^{2}$ Department of Food Science and Biotechnology, Kyungpook National University, Daegu 702-701, South Korea. \\ ${ }^{3}$ Department of Biochemistry and Molecular Biology, Monash University, Melbourne, VIC 3800, Australia. \\ ${ }^{4}$ Department of Applied Microbiology and Biotechnology, Yeungnam University, 280 Daehak-ro, Gyeongsan-si, Gyeongsangbuk-do 712-749, South \\ Korea. \\ ${ }^{5}$ Department of Energy and Materials Engineering, Dongguk University-Seoul, 30 Pildong-ro 1-gil, Seoul 04620, South Korea.
}

\begin{abstract}
Botanicals have been explored for their multitude of pharmaceutical and therapeutic potential. In this study, crude methanolic extract (MSSL) and organic soluble fractions of Syzygium samarangense leaves were evaluated for antioxidant activity using in vitro and in vivo models. To evaluate the antioxidant activity, total antioxidant capacity, free radical scavenging ability (DPPH) and reducing power, assays were conducted in vitro. Lipid peroxidation and activities of different antioxidant enzymes were measured in vivo. Quantitative phytochemical analyses such as the measurement of total phenolic, flavonoid, flavonol, and proanthocyanide contents were also evaluated. The ethyl acetate fraction (ESSL) showed significant effects in DPPH assay $\left(\mathrm{IC}_{50}=38.84 \pm 0.08 \mu \mathrm{g} / \mathrm{mL}\right.$ ) and reducing power assay. The effect of ESSL was found to be concentration-dependent with remarkable antioxidant activity as compared to other tested samples. In addition, administration of the extract/fractions (200 and $400 \mathrm{mg} / \mathrm{kg}$ body weight) to male Wistar rats increased the percentage of inhibition of reduced glutathione, superoxide dismutase and catalase significantly $(\mathrm{p}<0.05)$. The level of lipid peroxidation decreased at $400 \mathrm{mg} / \mathrm{kg}$ body weight after seven days in hepatotoxic rats. The pharmacological findings of this study clearly indicate that extracts and/or fractions of Syzygium samarangense leave could be a source of natural antioxidants.
\end{abstract}

Keywords: Antioxidant, flavonoids, phenol, proanthocyanidin, Syzygium samarangense.

\section{INTRODUCTION}

Syzygium samarangense (Blume) Merr. \& L.M. Perry is a plant species in the family Myrtaceae, commonly known as 'Wax Apple' native to the Malay Peninsula and the Andaman and Nicobar Islands (Peter et al., 2011). This plant is cultivated extensively for its fruits in tropical countries. In Bangladesh, it is locally called as 'Jamrul'. Different parts of $S$. samarangense such as leaves, fruits, root, and bark have been used for the treatment of various diseases including diabetes mellitus, bronchitis, asthma and inflammation syndromes (GuribFakim, 1991). The leaves and seeds of S. samarangense have been studied extensively for antimicrobial activities against some specific pathogenic microorganisms such as Pseudomonas aeruginosa, Klebsiella pneumonia and Cryptococcus neoformans (Chandrasekaran \& Vankatesalu, 2004). S. samarangense has shown potent free radical scavenging potential, antihyperglycaemic ability, antioxidant, antimutant, and anticancer activities (Mario et al., 2008). The leaves of S. samarangense contain a large amount of phytochemicals, including ellagitannins, flavanones, flavonol glycosides, proanthocyanidins, anthocyanidins, triterpenoids, chalcones, and volatile terpenoids (Shen et al., 2012).

\footnotetext{
* Corresponding author (vbajpai04@yahoo.com)
} 
S. samarangense is cultivated in India for its edible fruits that contains flavonol glycosides as well as epigallocatechin gallate (EGCG), epicatechin 3-O-gallate, and samarangenins $\mathrm{A}$ and $\mathrm{B}$, which has been reported to have potential antioxidant and antiinflammatory properties (Harborne \& Baxter, 1999; Asif, 2014). The pear-shaped fruits of $S$. samarangense with a subtly sweet taste and aromatic flavour are rich sources of phenolics, flavonoids and several antioxidant compounds (Moneruzzaman et al., 2012).

Antioxidants, as food additives, are used worldwide to improve the protection level against oxidative degradation of foods by free radicals (Gulcin et al., 2002). From the ancient time, spices have been added to different types of foods not only to improve flavours but also for their antioxidant capacities (Madsen \& Bertelsen, 1995). In recent times, studies have been performed to find plant extracts with natural antioxidant properties with less toxic effects. Although various synthetic antioxidants such as butylated hydroxytoluene (BHT) and butylated hydroxyanisole (BHA) have been used in food preservation, these substances are harmful for chronic human consumption (Ito et al., 1986; Lobo et al., 2010). Some researches have proved their possible toxic characteristics as a major threat for human health and the environment (Ito et al., 1986). The consumption of many fruits and vegetables can be beneficial as they are rich in flavonoids and phenolic compounds, which show potent antioxidant effects. Flavonoids include a large variety of compounds with a common diphenyl propane structure $\left(\mathrm{C}_{6} \mathrm{C}_{3} \mathrm{C}_{6}\right)$ with different phases of hydroxylation, oxidation, and substitution. These compounds are also called polyphenols, which commonly work as glycosides in plants (Pietta, 2000). The high antioxidant activity of anthocyanin is attributed to its complicated structure with easy donation capacity of a $\mathrm{H}$-atom from the aromatic hydroxyl group that improves the capacity to support the impaired electron via delocalisation around the pi-electron system. Furthermore, in case of inhibition of lipoprotein oxidation and platelet aggregation, anthocyanin works as an effective scavenger of reactive oxygen radicals, and in protection against cardiovascular diseases (Ghiselli et al., 1998).

The present study was designed to investigate the antioxidant properties of the methanolic extract (MSSL) and organic soluble fractions of $S$. samarangense leaves in various in vitro and in vivo models. The outcome of this research provides some specific insights on the significant use of $S$. samarangense as a natural source of antioxidant agents.

\section{METHODOLOGY}

\section{Chemicals}

2, 2-Diphenyl-1-picrylhydrazyl (DPPH), 2-deoxy-D-ribose and $\alpha$-tocopherol were purchased from Sigma-Aldrich (Steinheim, Germany). Gallic acid, ethylene-diaminetetra-acetic acid (EDTA), Folin-Ciocalteu's phenol reagent and hydrogen peroxide were purchased from Aldrich Chemical Company (Milwaukee, WI, USA). Thiobarbituric acid (TBA) was purchased from Sigma Company (St. Louis, MO, USA). All the other solvents and chemicals were of analytical grade. All the experiments were performed at room temperature of $28^{\circ} \mathrm{C}$.

\section{Preparation of $S$. samarangense extracts and fractions}

Leaves of $S$. samarangense were dried in an oven at $37 \pm 2{ }^{\circ} \mathrm{C}$ and powdered with a household grinder, passed through a no. 40 sieve and stored in an air tight container. The dried powdered material $(1.5 \mathrm{~kg})$ was refluxed with $\mathrm{MeOH}$ and placed in a shaking incubator at room temperature for $3 \mathrm{hrs}$. The filtrate was concentrated to dryness in vacuo at $40{ }^{\circ} \mathrm{C}$ to render the $\mathrm{MeOH}$ extract (MSSL; 490 g). This extract was suspended in $\mathrm{H}_{2} \mathrm{O}$ and then successively in $\mathrm{CH}_{2} \mathrm{Cl}_{2}$ (CSSL, $200 \mathrm{~g}$ ) and EtOAc (ESSL, $60 \mathrm{~g}$ ) fractions along with the residue $(120 \mathrm{~g})$ present in the aqueous $\left(\mathrm{H}_{2} \mathrm{O}\right)$ phase (WSSL). The resulting fractions including the aqueous fractions were evaporated to dryness by using a rotary evaporator followed by freeze drying. For further analysis, rest of the dried fractions were stored in brown coloured glass vials (in order to prevent oxidation) at $-20^{\circ} \mathrm{C}$.

\section{Experimental animals}

For the in vivo experiment, male Wistar rats with a mean weight of $170 \pm 6.4 \mathrm{~g}$ were used. The rats were purchased from Samtaco Korea (Osan, Korea). The animals were fed with a commercial diet (Purina Korea Inc., Seoul, Korea) and water ad libitum throughout the experiment. For the in vivo animal experiment, all protocols were approved by the institutional animal ethical committee and conducted in accordance with the Principles of Laboratory Animal Care (CCAC, 1993), and the internal guidelines of the Kyunpook National University Animal Ethical Committee were strictly followed. All the animals were acclimated to the laboratory environment for at least $1 \mathrm{wk}$ prior to commencement of the experiment. 
Quantitative measurement of major bioactive components of crude extract and solvent fractions

\section{Determination of total phenolic content}

Total phenolics were determined by using the FolinCiocalteu method as described previously (Palanisamy et al., 2008). An aliquot of the sample extract was mixed with $2 \mathrm{~mL}$ of Folin-Ciocalteu reagent $(1: 10 \mathrm{v} / \mathrm{v})$ and $2 \mathrm{~mL}$ $(75 \mathrm{~g} / \mathrm{L})$ of sodium carbonate. The tubes were vortexed for $15 \mathrm{~s}$ for colour development and the absorbance was measured at $760 \mathrm{~nm}$ with a UV-spectrophotometer (Shimadzu, USA). Samples of the extract were evaluated at a final concentration of $0.1 \mathrm{mg} / \mathrm{mL}$. Total phenolic contents were expressed in terms of gallic acid equivalent, $\operatorname{GAE}\left(\mathrm{Y}=0.0086 \mathrm{x}+0.0105, \mathrm{R}^{2}=0.9997\right), \mathrm{mg}$ of GAE $/ \mathrm{g}$ of dry extract.

\section{Determination of total flavonoids}

Flavonoids content was determined by the aluminum chloride colourimetric method (Chang et al., 2002). To $0.5 \mathrm{~mL}$ of the sample, $1.5 \mathrm{~mL}$ of methanol, $100 \mu \mathrm{L}$ of $10 \%$ aluminium chloride, $100 \mu \mathrm{L}$ of $1 \mathrm{M}$ potassium acetate solution and $2.8 \mathrm{~mL}$ of distilled water were added. After $1 \mathrm{~h}$, the samples were incubated for $30 \mathrm{~min}$ at room temperature, and the absorbance was measured at $420 \mathrm{~nm}$. The extract samples were evaluated at a final concentration of $0.1 \mathrm{mg} / \mathrm{mL}$. Total flavonoids content was expressed in terms of quercetin equivalent, QAE $\left(\mathrm{Y}=0.0135 \mathrm{x}+0.0085, \mathrm{R}^{2}=0.9984\right), \mathrm{mg}$ of $\mathrm{QAE} / \mathrm{g}$ of dry extract.

\section{Determination of total flavonols}

Total flavonols in the extract samples were estimated using the method by Kumaran and Karunakaran (2007). To $2.0 \mathrm{~mL}$ of sample (standard), $2.0 \mathrm{~mL}$ of $2 \% \mathrm{AlCl}_{3}$ in ethanol and $3.0 \mathrm{~mL}$ of sodium acetate $(50 \mathrm{~g} / \mathrm{L})$ were added. The absorption at $440 \mathrm{~nm}$ was read after $2.5 \mathrm{~h}$ at $20{ }^{\circ} \mathrm{C}$. Extract samples were evaluated at a final concentration of $0.1 \mathrm{mg} / \mathrm{mL}$. Total content of flavonols was expressed in terms of quercetin equivalent, QAE $\left(\mathrm{Y}=0.0255 \mathrm{x}+0.0069, \mathrm{R}^{2}=0.9995\right), \mathrm{mg}$ of $\mathrm{QAE} / \mathrm{g}$ of dry extract.

\section{Determination of total proanthocyanidins}

Determination of the proanthocyanidin content was based on the procedure reported by Aiyegoro and Okoh (2010). A volume of $0.5 \mathrm{~mL}$ of $0.1 \mathrm{mg} / \mathrm{mL}$ extract solution was mixed with $3 \mathrm{~mL}$ of $4 \%$ vanillin-methanol solution and $1.5 \mathrm{~mL}$ of hydrochloric acid, and the mixture was allowed to stand for $15 \mathrm{~min}$ at room temperature. The absorbance was measured at $500 \mathrm{~nm}$. Extract samples were evaluated at a final concentration of $0.1 \mathrm{mg} / \mathrm{mL}$. Total content of proanthocyanidin was expressed in terms of catechin equivalent, $\mathrm{CAE}(\mathrm{Y}=0.567 \mathrm{x}-0.024$, $\left.\mathrm{R}^{2}=0.9801\right)$, $\mathrm{mg}$ of $\mathrm{CAE} / \mathrm{g}$ of dry extract.

\section{In vitro antioxidant activity}

\section{Determination of total antioxidant capacity}

Total antioxidant activity of the $\mathrm{MeOH}$ extract and several fractions was evaluated by the phosphomolybdenum method according to a procedure reported previously (Prieto et al., 1999). The experiment method was based on the reduction of Mo (VI) to Mo (V) by the extract and subsequent formation of a green phosphate/Mo (V) complex at acidic $\mathrm{pH}$. The antioxidant activity was expressed as the number of equivalents of ascorbic acid using the following formula:

Antioxidant activity: $\mathrm{C}=(\mathrm{C} \times \mathrm{V}) / \mathrm{m}$

where $\mathrm{C}$ is represented as the total antioxidant activity in $\mathrm{mg} / \mathrm{g}$ of plant leaf extracts in ascorbic acid. $\mathrm{C}$ is the concentration of the ascorbic acid established from the calibration curve in $\mathrm{mg} / \mathrm{mL}$; V is the volume of the extract in $\mathrm{mL}$ and $\mathrm{m}$ is the weight of pure plant extract in grams.

\section{Determination of DPPH free radical scavenging activity}

Free radical scavenging activity of the extracts/fractions, based on the scavenging activity of the stable DPPH free radical, was determined by a previously described method (Braca et al., 2001). Plant extract/fractions $(0.1 \mathrm{~mL})$ were added to $3 \mathrm{~mL}$ of $0.004 \% \mathrm{MeOH}$ solution of DPPH. Absorbance at $517 \mathrm{~nm}$ was measured after $30 \mathrm{~min}$ and the percentage inhibition activity was calculated from the following formula:

Inhibition $(\%)=\left[\left(\mathrm{A}_{0}-\mathrm{A}_{1}\right) / \mathrm{A}_{0}\right] \times 100$

where $A_{0}$ is the absorbance of the control and $A_{1}$ is the absorbance of the extract/ standard. $\mathrm{IC}_{50}$ value was calculated from the equation of the line obtained by plotting a graph of concentration $(\mu \mathrm{g} / \mathrm{mL})$ versus percentage inhibition.

\section{Reducing power assay}

The reducing power of the extract/ fractions was determined according to the method previously described by Oyaizu (1986). Extracts at different concentrations in $1 \mathrm{~mL}$ of $10 \%$ DMSO were mixed with $2.5 \mathrm{~mL}$ of phosphate buffer $(0.2 \mathrm{M}, \mathrm{pH} 6.6)$ and $2.5 \mathrm{~mL}$ of potassium ferricyanide $[\mathrm{K} \mathrm{Fe}(\mathrm{CN})](1 \%)$, and then the 
mixture was incubated at $50{ }^{\circ} \mathrm{C}$ for $30 \mathrm{~min}$. Afterwards, $2.5 \mathrm{~mL}$ of trichloroacetic acid (10\%) was added to the mixture, which was then centrifuged at 3,000 rpm for $10 \mathrm{~min}$. Finally, $2.5 \mathrm{~mL}$ of the supernatant solution was mixed with $2.5 \mathrm{~mL}$ of distilled water and $0.5 \mathrm{~mL}$ of $\mathrm{FeCl}_{3}$ $(0.1 \%)$ and the absorbance was measured at $700 \mathrm{~nm}$. Increased absorbance of the reaction mixture indicated increased reducing power.

\section{In vivo antioxidant activity}

\section{Animal grouping and extract administration}

Twenty male Wistar rats were randomised into 7 groups consisting of 5 in each group. Group 1 served as the control and was given $0.5 \mathrm{~mL}$ of saline per day for 7 days with the aid of oropharyngeal cannulae. Group 2 animals served as the hepatotoxic control, treated with $\mathrm{CCl}_{4}$ in a single dose of $0.5 \mathrm{~mL}$ administered orally for 7 days. Group 3 to 6 and 7 were treated like the control except that they received $0.5 \mathrm{~mL}$ of the extract corresponding to 200 and $400 \mathrm{mg} / \mathrm{kg}$ body weight, and $100 \mathrm{mg} / \mathrm{kg}$ of ascorbic acid, respectively. Group 3 to 6 and 7 were given $0.5 \mathrm{~mL}$ of $\mathrm{CCl}_{4}$ on the $7^{\text {th }}$ day after $6 \mathrm{~h}$ of extract administration. All the animals from each group were sacrificed by ether anesthesia, $24 \mathrm{hrs}$ after their respective 21 daily doses of the extract and saline. The liver from each animal was excised and rinsed in ice cold $0.25 \mathrm{M}$ sucrose solution. A $10 \%(\mathrm{w} / \mathrm{v})$ homogenate was prepared in $0.05 \mathrm{M}$ phosphate buffer $(\mathrm{pH} \mathrm{7})$ and centrifuged at 5,000 rpm for $60 \mathrm{~min}$ at $4{ }^{\circ} \mathrm{C}$. The supernatant obtained was used for the estimation of catalase, superoxide dismutase, lipid peroxidation (TBARS) and reduced glutathione.

\section{Lipid peroxidation assay}

Lipid peroxidation in the liver was estimated calorimetrically by thiobarbituric acid reactive substances (TBARS) using a modified method (Niehius \& Samuelson, 1968). In this method, $0.1 \mathrm{~mL}$ of liver homogenate $(10 \% \mathrm{w} / \mathrm{v})$ was treated with $2 \mathrm{~mL}$ of $1: 1: 1$ TBA: TCA: $\mathrm{HCl}$ reagent $(0.37 \%$ thiobarbituric acid, $15 \%$ trichloroacetic acid and $0.25 \mathrm{~N} \mathrm{HCl}$ ). All the tubes were placed in a boiling water bath for $30 \mathrm{~min}$ and cooled. The amount of malondialdehyde formed in each of the samples was assessed by measuring the absorbance of the clear supernatant at $535 \mathrm{~nm}$ against reference blank. Percentage inhibition was calculated using the following equation:

$\%$ lipids inhibition $=\left\{\mathrm{A}_{\mathrm{o}}-\mathrm{A}_{1}\right\} / \mathrm{A}_{\mathrm{o}} \times 100$

where $A_{o}$ is the absorbance of the control and $A_{1}$ is the absorbance of the sample extract.

\section{Estimation of reduced glutathione (GSH) level}

The GSH level of the liver tissue was determined as described by Ellman et al. (1951). The tissue homogenate (in $0.1 \mathrm{M}$ phosphate buffer, $\mathrm{pH}$ 7.4) was taken and an equal volume of $20 \%$ trichloroacetic acid (TCA) containing $1 \mathrm{mM}$ EDTA was added to precipitate the tissue proteins. The mixture was allowed to stand for $5 \mathrm{~min}$ prior to centrifugation for $10 \mathrm{~min}$ at $2,000 \mathrm{rpm}$. The supernatant $(200 \mu \mathrm{L})$ was then transferred to a new set of test tubes and added with $1.8 \mathrm{~mL}$ of the Ellman's reagent [5,50 -dithiobis-2- nitrobenzoic acid $(0.1 \mathrm{mM})$ prepared in $0.3 \mathrm{M}$ phosphate buffer with $1 \%$ of sodium citrate solution]. All the test tubes were made up to the volume of $2 \mathrm{~mL}$. After completion of the total reaction, absorbance was measured at $412 \mathrm{~nm}$ against blank and the GSH value was expressed as $\mu \mathrm{g} / \mathrm{g}$ of liver tissues.

\section{Estimation of superoxide dismutase (SOD) levels}

The method described by McCord and Fridovich (1969) was used. To $50 \mu \mathrm{L}$ of the lysate, $75 \mathrm{mM}$ of Tris- $\mathrm{HCl}$ buffer (pH 8.2), $30 \mathrm{mM}$ EDTA and $2 \mathrm{mM}$ of pyrogallol were added. An increase in absorbance was recorded at $420 \mathrm{~nm}$ for $3 \mathrm{~min}$ by the spectrophotometer. One unit of enzyme activity was $50 \%$ inhibition of the rate of auto-oxidation of pyrogallol as determined by change in absorbance $/ \mathrm{min}$ at $420 \mathrm{~nm}$. The activity of SOD was expressed as units/mg protein.

\section{Estimation of catalase levels}

Catalase activity in erythrocyte lysate can be determined using a previously reported method (Aebi, 1984). $50 \mu \mathrm{L}$ of the lysate was added to a cuvette containing $2 \mathrm{~mL}$ of phosphate buffer (pH 7.0) and $1 \mathrm{~mL}$ of $30 \mathrm{mM}$ $\mathrm{H}_{2} \mathrm{O}_{2}$. Catalase activity was measured at $240 \mathrm{~nm}$ for $1 \mathrm{~min}$ using the spectrophotometer. The molar extinction coefficient of $43.6 / \mathrm{M} / \mathrm{cm}$ for $\mathrm{H}_{2} \mathrm{O}_{2}$ was used to determine the catalase activity. One unit of activity was equal to $1 \mathrm{mM}$ of $\mathrm{H}_{2} \mathrm{O}_{2}$ degraded per min and was expressed as units / $\mathrm{mg}$ protein.

\section{Statistical analysis}

All data were expressed as mean \pm standard error of mean (S.E.M.). Statistical significance was analysed by one-way analysis of variance (ANOVA) followed by Duncan's multiple range test of significance. All statistical analyses were performed with Prism 4.0 (GraphPad software Inc., San Diego, CA). $\mathrm{p}<0.05$ was considered to be significant. 


\section{RESULTS} Polyphenolic, flavonoid, proanthocyanidin and
flavonol compounds

The results of total phenol, total flavonoid, total flavonol and total proanthocyanidin contents in the methanolic extract and organic soluble fractions of $S$. samarangense leaves have been presented in Table 1. The contents of total phenolic, flavonoid, proanthocyanidin and flavonols in MSSL were found to be $100.48 \pm 0.21,111.40 \pm 0.23$, $9.26 \pm 0.45,46.40 \pm 0.70 \mathrm{mg} / \mathrm{g}$, respectively. Soluble solvent fractions isolated from MSSL also showed varied total phenolic and flavonoid contents. Among the fractions, ESSL showed the highest total phenolic content $(148.57 \pm 0.22 \mathrm{mg} / \mathrm{g})$ followed by WSSL (48.43 $\pm 0.41 \mathrm{mg} / \mathrm{g})$, and CSSL $(38.86 \pm 0.15 \mathrm{mg} / \mathrm{g})$. In the case of flavonoid content ESSL again showed the highest flavonoid content $(207.40 \pm 0.12 \mathrm{mg} / \mathrm{g})$ followed by CSSL $(64.40 \pm 0.32 \mathrm{mg} / \mathrm{g})$ and WSSL $(30.20 \pm 0.24 \mathrm{mg} / \mathrm{g})$. The results showed that ESSL $(16.87 \pm 0.58 \mathrm{mg} / \mathrm{g})$ had the highest content of total proanthocyanidin compared to CSSL (6.81 $\pm 0.02 \mathrm{mg} / \mathrm{g})$ and WSSL $(2.84 \pm 0.33 \mathrm{mg} / \mathrm{g})$, while the content of total flavonol in the organic fractions decreased in the order of CSSL $(71.47 \pm 0.47)>$ ESSL $(57.80 \pm 0.05)>$ WSSL $(16.00 \pm 0.55)$. Therefore, it can be suggested that among all the solvent soluble fractions, ESSL was potent for the tested compounds.

Table 1: Total amount of phenolic compounds, flavonoids, flavonols, proanthocyanidin and total antioxidant capacity of methanolic extracts and its various organic soluble fractions of Syzygium samarangense leaves

\begin{tabular}{lcccc}
\hline Sample & $\begin{array}{c}\text { Total phenol mg/g plant } \\
\text { extracts (in GAE) }\end{array}$ & $\begin{array}{c}\text { Total flavonoid mg/g plant } \\
\text { extracts (in QAE) }\end{array}$ & $\begin{array}{c}\text { Total proanthocyanidin mg/g } \\
\text { plant extracts (in CAE) }\end{array}$ & $\begin{array}{c}\text { Total flavonols mg/g plant } \\
{\text { extracts (in QAE })^{\mathrm{b}}}^{\mathrm{b}}\end{array}$ \\
\hline MSSL & $100.48 \pm 0.21^{\mathrm{c}}$ & $111.40 \pm 0.23^{\mathrm{d}}$ & $9.26 \pm 0.45^{\mathrm{a}}$ & $46.40 \pm 0.7^{\mathrm{b}}$ \\
CSSL & $38.86 \pm 0.15^{\mathrm{b}}$ & $64.40 \pm 0.32^{\mathrm{c}}$ & $6.81 \pm 0.02^{\mathrm{a}}$ & $71.47 \pm 0.47^{\mathrm{d}}$ \\
ESSL & $148.57 \pm 0.22^{\mathrm{c}}$ & $207.40 \pm 0.12^{\mathrm{d}}$ & $16.87 \pm 0.58^{\mathrm{a}}$ & $57.80 \pm 0.05^{\mathrm{b}}$ \\
WSSL & $48.43 \pm 0.41^{\mathrm{d}}$ & $30.20 \pm 0.24^{\mathrm{c}}$ & $2.84 \pm 0.33^{\mathrm{a}}$ & $16.00 \pm 0.55^{\mathrm{b}}$ \\
& & & & \\
\hline
\end{tabular}

Superscripts in different columns of same row not sharing a common superscript are significantly different at $\mathrm{p}<0.05$ by Duncan's multiple range test. ${ }^{a}$ Galic acid equivalents (GAE, $\mathrm{mg} / \mathrm{g}$ of each extract) for the total phenolic content; ${ }^{\mathrm{b}}$ quercetin equivalent (QAE, $\mathrm{mg} / \mathrm{g}$ of each extract) for the total flavonoid and flavonol content; ${ }^{\circ}$ cathecin equivalent (CAE, $\mathrm{mg} / \mathrm{g}$ of each extract) for the total catechin; MSSL = methanolic extract; $\mathrm{CSSL}=$ dichloromethane fraction; $\mathrm{ESSL}=$ ethyl acetate fraction; $\mathrm{WSSL}=$ water fractions of Syzygium samarangense leaves. Values are means $\pm \mathrm{SD}$ of three experiments.

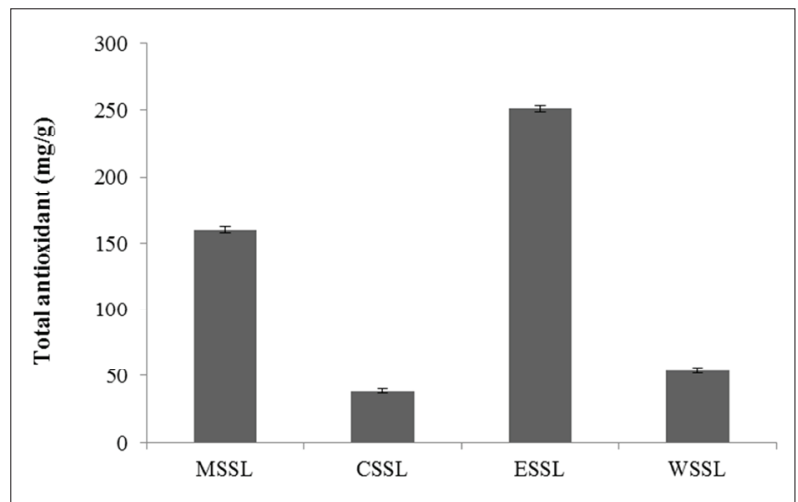

Figure 1: Total antioxidant capacity of extract/fractions of Syzygium samarangense leaves is expressed as the number of equivalents of ascorbic acid (ASC, mg/g of each dry extract). Values are means $\pm \mathrm{SD}$ of three experiments

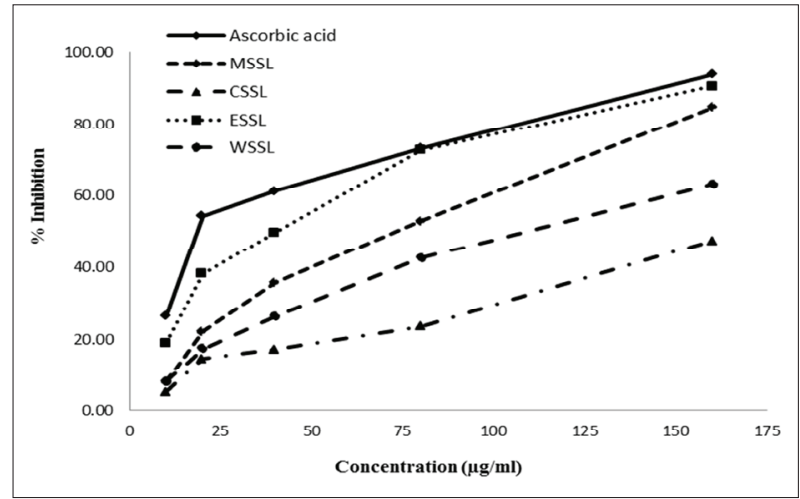

Figure 2: DPPH scavenging activity of extract/fractions of Syzygium samarangense leaves. Results are mean \pm SEM of three parallel measurements. 


\section{Total antioxidant capacity}

Total antioxidant capacity of the methanolic extract and organic soluble fractions of $S$. samarangense is given in Figure 1. MSSL showed the total antioxidant activity as $159.99 \pm 0.33 \mathrm{mg} / \mathrm{g}$. The total antioxidant capacity of various fractions of $S$. samarangense was also expressed as the number of equivalents of ascorbic acid (ASC, mg/g of each dry extract) and was found to be the highest for ESSL $(251.01 \pm 0.23 \mathrm{mg} / \mathrm{g})$ followed by WSSL (54.12 $\pm 0.02 \mathrm{mg} / \mathrm{g})$ and CSSL $(38.7 \pm 0.45 \mathrm{mg} / \mathrm{g})$ equivalents of ascorbic acid. It was observed that MSSL has higher total antioxidant activity than the other solvent soluble fractions (ESSL, WSSL and CSSL).

\section{DPPH radical scavenging activity}

Figure 2 shows the dose-response curve of DPPH radical scavenging activity of various fractions of S. samarangense leaves in comparison with ascorbic acid. All the fractions of $S$. samarangense leaves demonstrated proton-donating activity. In this assay, ESSL showed the highest DPPH scavenging activity with an $\mathrm{IC}_{50}$ value of $38.84 \pm 0.28 \mu \mathrm{g} / \mathrm{mL}$, followed by WSSL with an $\mathrm{IC}_{50}$ value of $137.63 \pm 0.08 \mu \mathrm{g} / \mathrm{mL}$. CSSL had no activity within the experimental concentration range whereas standard ascorbic acid showed an $\mathrm{IC}_{50}$ value of 18.84 $\mu \mathrm{g} / \mathrm{mL}$. MSSL also showed potent activity with an $\mathrm{IC}_{50}$ value of $75.24 \pm 0.16 \mu \mathrm{g} / \mathrm{mL}$, which is lesser than ESSL and ascorbic acid but higher than WSSL and CSSL.

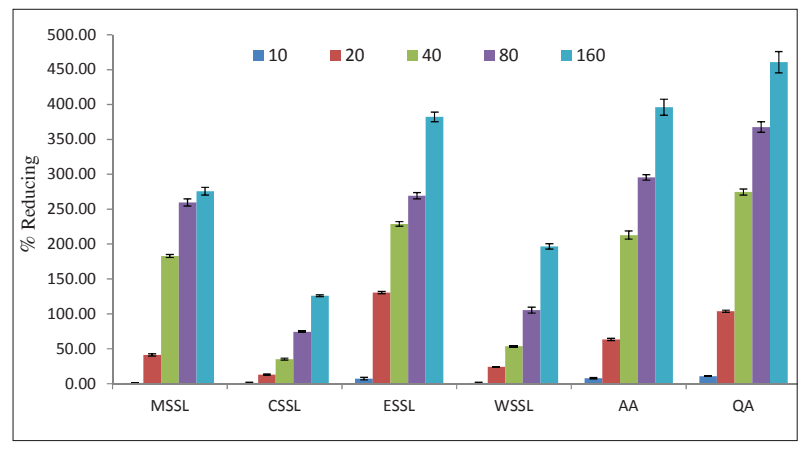

Figure 3: Reducing power of $\mathrm{MeOH}$ extract, fractions of Syzygium samarangense, ascorbic acid (AA) and gallic acid (GA) by spectrophotometric detection of $\mathrm{Fe}^{3+}$ to $\mathrm{Fe}^{2+}$ transformation. Results are mean $\pm \mathrm{SEM}$ of three parallel measurements.
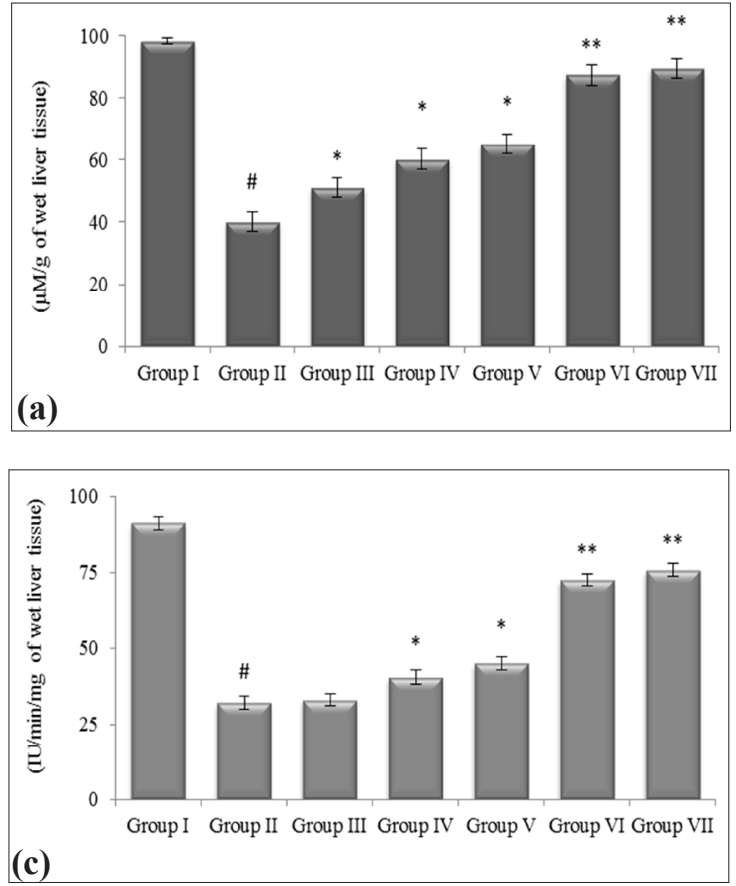
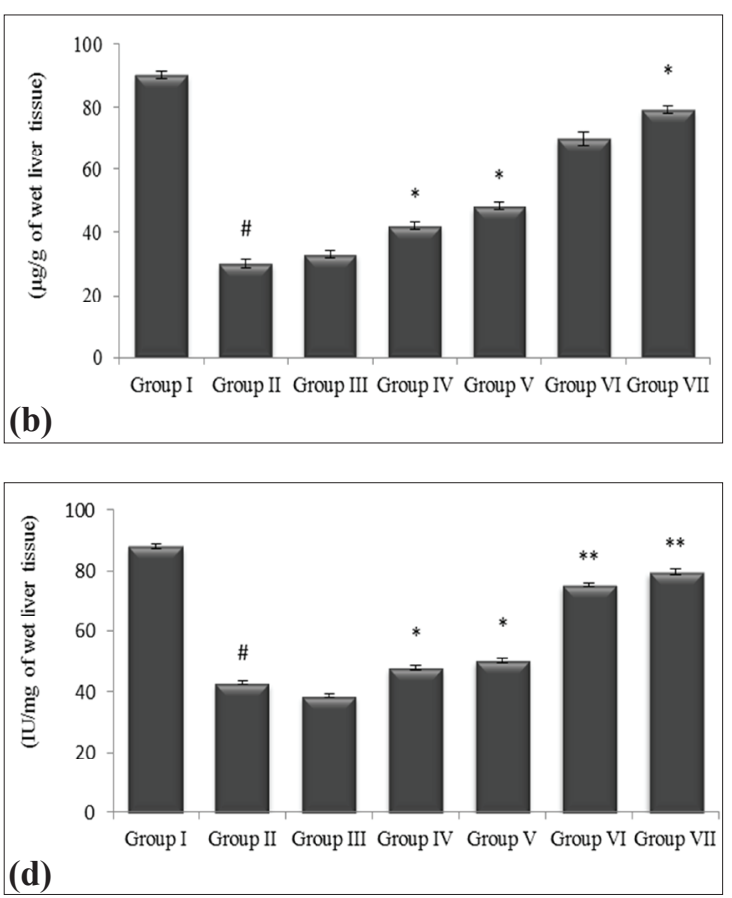

Figure 4: Effect of Syzygium samarangense on lipid peroxidase (MDA) (a); reduced glutathione (GSH) (b); superoxide dismutase (SOD) (c); and catalase (CAT) (d) in $\mathrm{CCl}_{4}$ treated rat. Each point represent the mean $\pm \mathrm{SEM}$. ( $\mathrm{n}=6$ mice per group); $\# \mathrm{p}<0.05$ statistically significant when compared with normal saline group; $* \mathrm{p}<0.05$ statistically significant when compared with $\mathrm{CCl}_{4}$ treated control group; $* * \mathrm{p}<0.005$ statistically significant when compared with $\mathrm{CCl}_{4}$ treated control group. Group I animals received normal saline $(5 \mathrm{~mL} / \mathrm{kg})$; group II received $\mathrm{CCl}_{4}$ treated control; group VII received ascorbic acid $100 \mathrm{mg} / \mathrm{kg}$ body weight; groups III and IV were treated with 200 and $400 \mathrm{mg} / \mathrm{kg}$ body weight (p.o.) of the MSSL, respectively; group V and VI were treated with 200 and $400 \mathrm{mg} / \mathrm{kg}$ body weight (p.o.) of the ESSL, respectively. 


\section{Reducing power ability}

For the measurement of reductive ability, $\mathrm{Fe}^{3+}$ to $\mathrm{Fe}^{2+}$ transformation in the presence of extract and organic fractions was investigated. Similar to the antioxidant activity, the reducing power of $S$. samarangense leaves increased with increasing concentration of the sample. Figure 3 shows the reductive capabilities of the $S$. samarangense leaf extract/fractions compared with quercetin and ascorbic acid. The extract and all the fractions derived from $S$. samarangense showed higher activities at the tested concentrations and these differences were statistically significant $(p<0.05)$.

Lipid peroxidation (LPO), enzymatic (CAT, SOD) and non-enzymatic (GSH) antioxidant system

Reduced activities of enzymatic (CAT, SOD) and nonenzymatic (GSH) antioxidant systems along with the lipid peroxidation (LPO) level of liver homogenate are summarised in Figure 4. In this assay, MSSL at the concentration of $400 \mathrm{mg} / \mathrm{kg}$ showed reduced lipid peroxidation at the level of $60.25 \pm 1.10$. After administration of the solvent soluble fraction ESSL at $400 \mathrm{mg} / \mathrm{kg}$ and ascorbic acid $(100 \mathrm{mg} / \mathrm{kg})$ to $\mathrm{CCl}_{4}$ treated rats, the level of lipid peroxidation decreased $(\mathrm{p}<0.05)$ by $87.32 \pm 2.10$ and $89.59 \pm 1.04$, respectively relative to the $\mathrm{CCl}_{4}$ control group (Figure $4 \mathrm{a}$ ). Reduced glutathione levels were found to be significantly $(p<0.05)$ elevated towards the normal level upon administration of crude methanol extract (MSSL) at $400 \mathrm{mg} / \mathrm{kg}$ when compared to the $\mathrm{CCl}_{4}$ control group (Figure $4 \mathrm{~b}$ ).

Administration of methanol crude extract (MSSL) at 200 and $400 \mathrm{mg} / \mathrm{kg}$ drastically $(\mathrm{p}<0.05)$ increased the levels of SOD and CAT in a dose-dependent manner (Figures $4 \mathrm{c}$ and $4 \mathrm{~d}$, each $3^{\text {rd }} \sim 4^{\text {th }}$ lane) relative to that of the $\mathrm{CCl}_{4}$ control group. The solvent soluble fraction (ESSL) showed almost similar activity to the standard compound ascorbic acid for both parameters (Figure 4, each $7^{\text {th }}$ lane).

\section{DISCUSSION}

It is well known that phenolic compounds contribute to the quality and nutritional value of food in terms of modifying the colour, taste, aroma, and flavour as well as exerting health beneficial effects. Examining the polyphenolic content of Syzygium samarangense may be of great benefit to understand the health aspects of both traditional and modern uses of $S$. samarangense. Flavonoids are hydroxylated phenolics with potent antioxidant ability, which helps in scavenging free radicals and preventing oxidative cell damage (Gupta et al., 2005). It is estimated that human beings consume between a few hundred milligrams to one gram of flavonoids every day. The range of biological activity of flavonoids is large; in addition to scavenging free radicals and reactive oxygen species (ROS), flavonoid actions include anti-inflammatory, antiallergenic, antiviral, antibacterial, antifungal, antitumor, and antihaemorrhagic (Ozgen et al., 2010). Flavonoids also inhibit a number of enzymes, including aldose reductase, $\alpha$-glucosidase, xanthine oxidase, monooxygenase, lipoxegenase and cyclooxygenase (Aiyegoro \& Okoh, 2010). In this study, the ESSL fraction of $S$. samarangense showed the presence of higher amount of flavonoids than the other solvent fractions investigated. In addition, proanthocyanidins are a group of polyphenolic bioflavonoids, which have a protective effect in eliminating hydroxyl radicals (Pataki et al., 2002). The proanthocyanidin content was relatively high in the ESSL extract. This is in agreement with the findings of Loots et al. (2007), who reported a higher concentration of proanthocyanidins (polyphenols) in the leaf gel extract of $A$. ferox, which may serve as a potential source of bioactive agents in the treatment of oxidative stress or free radical associated diseases.

The upshots of oxidative stress are serious and sometimes manifested by increased activities of enzymes involved in oxygen detoxification (Gupta et al., 2005). Therefore, the identification of new antioxidants may reduce the risk of various chronic diseases involving free radicals. To determine the efficacy of natural antioxidants either as a pure compound or as a plant extract, a great number of in vitro methods have been developed in which antioxidant compounds act via several mechanisms. The knowledge of total antioxidant activity can be useful in the analysis of changes in plasma antioxidant activity related to oxidative stress, or in the understanding of structure-activity relationships of pure antioxidant species. The phosphomolybdenum method was based on the reduction of Mo (VI) to Mo (V) by the compounds having antioxidant properties and is successfully used to quantify vitamin $\mathrm{E}$ in various samples (Prieto et al., 1999).

DPPH is a stable free radical that accepts an electron or hydrogen radical to become a stable diamagnetic molecule (Lompo et al., 2007), and is usually used as a substrate to evaluate the antioxidant activity of a variety of compounds (Braca et al., 2001). Based on the data obtained in this study, DPPH radical scavenging activity of ESSL was found to be $\mathrm{IC}_{50} 38.84 \pm 0.28 \mu \mathrm{g} / \mathrm{mL}$. Moreover, it was revealed that ESSL showed proton 
donating ability, confirming its role as a free radical inhibitor or scavenger. A direct correlation between the antioxidant capacity and the reducing power of certain plant extracts has been reported (Nakayama et al., 1993). The reducing properties are generally associated with the presence of reducing groups, which have been shown to exert antioxidant action by breaking the free radical chain upon donating a hydrogen atom (Tanaka et al., 1988). Since a substance may act as an antioxidant due to its ability to reduce ROS by donating hydrogen atoms (Jayprakash et al., 2001), the ferric reducing property of plant extracts (Figure 3) implies that they are capable of donating hydrogen atoms in a dose-dependent manner.

$\mathrm{CCl}_{4}$ is one of the most commonly used hepatotoxins in experimental studies of liver damage (Lee et al., 2001). The hepatotoxic effect of this chemical is mostly based on membrane lipid peroxidation. Consequently, the trichloromethyl radical leads to severe cell damage (Curtis \& Mortiz, 1972). In the present study, a single dose of $\mathrm{CCl}_{4}$ developed significant hepatic damage and oxidative stress, leading to increased lipid peroxidation. The treatment with different fractions of $S$. samarangense leaves was able to reduce the level of lipid peroxides in a dose-dependent manner as compared with the hepatotoxic group.

Superoxide dismutase (SOD) has been reported as one of the most important enzymes in the enzymatic antioxidant defense system (Curtis \& Mortiz, 1972). It removes superoxide anions by converting it to hydrogen peroxide and prevents the toxic effect caused by this radical. In this assay, $\mathrm{CCl}_{4}$ induced hepatic damage led to the decrease in the percentage inhibition of SOD. However, the administration of plant extract/fractions increased the percentage inhibition of SOD, revealing the efficient protective mechanism of this plant.

Catalase is another antioxidant enzyme, which is widely distributed in animal tissues. Catalase decomposes $\mathrm{H}_{2} \mathrm{O}_{2}$ and protects the cells from highly reactive hydroxyl radicals (Chance \& Greenstein, 1992). Yeh and Yen (2006) reported that four different phenolic acids were able to induce antioxidant enzymes including SOD, catalase and glutathione peroxidase. In the present study, it was found that when administered, $S$. samarangense increased the percentage inhibition of SOD, probably due to the presence of phenolic compounds in its extract/ fractions.

Reduced glutathione (GSH) is a tripeptide, nonenzymatic biological antioxidant present in the liver. It protects cellular proteins against ROS generated from the exposure to $\mathrm{CCl}_{4}$ (Arivazhagan et al., 2000). In this assay, the ability of the extract/fractions derived from $S$. samarangense to reactivate the hepatic glutathione reductase was reflected by decreasing the level of lipid peroxidation, and the results were in strong agreement with earlier reports (Bhandarkar \& Khan, 2004).

In addition, Manaharan et al. (2013) also observed insulin-like and/or insulin-sensitising effects of Syzygium aqueum leaf extract and its six bioactive compounds (4-hydroxybenzaldehyde, myricetin-3-O-rhamnoside, europetin-3-O-rhamnoside, phloretin, myrigalone-G and myrigalone-B) in 3T3-L1 adipocytes. Syzygium aqueum leaf extract $(0.04-5 \mu \mathrm{g} / \mathrm{mL})$ and its six bioactive compounds $(0.08-10 \mu \mathrm{M})$ atnon-cytotoxic concentrations effectively enhanced adipogenesis, as well as stimulated the glucose uptake and increased adiponectin secretion in 3T3-L1 adipocytes. In a further study, Manaharan et al. (2012) isolated and identified six flavonoid compounds, 4-hydroxybenzaldehyde, myricetin-3-Orham-noside, europetin-3-O-rhamnoside, phloretin, myrigalone- $\mathrm{G}$ and myrigalone- $\mathrm{B}$, from the ethanolic leaf extracts of $S$. aqueum. Compounds myricetin-3-Orham-noside, and europetin-3-O-rhamnoside showed high inhibitory activities with $\mathrm{EC}_{50}$ values of $1.1 \mathrm{lM}$ and $1.9 \mathrm{lM}$ against $\alpha$-glucosidase, and $\mathrm{EC}_{50}$ values of $1.9 \mathrm{IM}$ and $2.3 \mathrm{lM}$ against $\alpha$-amylase, respectively. These findings provide a strong rationale to establish $S$. aqueum's capability as an antihyperglycaemic agent. Similarly, Amor et al. (2005) isolated a dihydrochalcone flavonoid compound from the leaves of $S$. samarangense with anticholinesterase activity. Raga et al. (2011) also isolated a few terpene compounds including cycloartenyl stearate, lupenyl stearate, sitosteryl stearate, and 24-methylenecycloartanyl stearate from the leaves of $S$. samarangense, which exhibited potent analgesic and anti-inflammatory activities at effective doses of $6.25 \mathrm{mg} / \mathrm{kg}$ body weight and $12.5 \mathrm{mg} / \mathrm{kg}$ body weight, respectively. Further, Reddy and Jose (2011) analysed the chemical composition and antibacterial activity of the volatile oil from the leaves of $S$. samarangense, supporting its biological significance.

\section{CONCLUSION}

The results of the present study indicate that the methanolic extract (MSSL) and various solvent soluble fractions of Syzygium samarangense leaves exhibit interesting antioxidant properties in various in vitro and in vivo models. The MSSL showed higher antioxidant activity than the other solvent soluble fractions. Among all the solvent fractions, ESSL showed better results than others in each tested antioxidant assay, suggesting it to be a potential candidate of significant antioxidant 
efficacy. These findings reinforce the suggestions that $S$. samarangense could be a suitable candidate for the treatment of various free radical mediated diseases. However, the results of this investigation does not reveal which chemical compound is responsible for the aforementioned activity.

\section{REFERENCES}

1. Aebi H. (1984). Catalase in vitro. Methods in Enzymology (ed. L. Packer), volume 105, pp. 121 - 126. Academic Press Inc., San Diego, CA, USA.

2. Aiyegoro O.A. \& Okoh A.I. (2010). Preliminary phytochemical screening and in vitro antioxidant activities of the aqueous extract of Helichrysum longifolium. BMC Complementary and Alternative Medicine 10: 21 - 28. DOI: https://doi.org/10.1186/1472-6882-10-21

3. Amor E.C., Villaseñor I.M., Nawaz S.A., Hussain M.S. \& Choudhary M.I. (2005). A dihydrochalcone from Syzygium samarangense with anticholinesterase activity. Philippine Journal of Science 134: 105 - 111.

4. Arivazhagan S., Balasenthil S. \& Nagini S. (2000). Garlic and neem leaf extracts enhance hepatic glutathione and glutathione dependent enzymes during N-methyl-N nitrosoguanidine (MNNG) induced gastric carcinogenesis. Phytotherapy Research 14: 291 - 293.

5. Asif M. (2014). Bioactive phytochemical constituents of some edible fruits of Myrtaceae family. American Journal of Nutrition Research 1: 1 - 17.

6. Bhandarkar M.R. \& Khan A. (2004). Antihepatotoxic effect of Nymphaea stellata Willd, against carbon tetrachlorideinduced hepatic damage in albino rats. Journal of Ethnopharmacology 91(1): $61-64$.

DOI: https://doi.org/10.1016/j.jep.2003.11.020

7. Braca A., Tommasi N.D., Bari L.D., Pizza C., Politi M. \& Morelli I. (2001). Antioxidant principles from Bauhinia terapotensis. Journal of Natural Products 64: $892-895$. DOI: https://doi.org/10.1021/np0100845

8. Canadian Council on Animal Care (CCAC) (1993). Guide to the Care and Use of Experimental Animals, volume 1. Canadian Council on Animal Care, Ottawa, Ontario, Canada.

9. Chance B. \& Greenstein D.S. (1992). The mechanism of catalase actions steady state analysis. Archives of Biochemistry and Biophysics 37: $301-339$.

10. Chandrasekaran M. \& Vankatesalu V. (2004). Antibacterial and antifungal activities of Syzygium jambolanum seeds. Journal of Ethnopharmacology 91(1): 105 - 108.

DOI: https://doi.org/10.1016/j.jep.2003.12.012

11. Chang C.C., Yang M.H., Wen H.M. \& Chern J.C. (2002). Estimation of total flavonoid content in propolis by two complementary colorimetric methods. Journal of Food Drug and Analysis 10: 178 - 182.

12. Curtis J.J. \& Mortiz M. (1972). Serum enzymes derived from liver cell fraction and carbon tetrachloride intoxication in rats. Gastroenterology 62: $84-92$.

13. Ellman G.L. (1951). Tissue sulfhydryl groups. Archives of Biochemistry and Biophysics 82: $70-77$.
14. Ghiselli A., Nardini M. \& Baldi A. (1998). Antioxidant activity of different phenolic fraction separated from an Italian red wine. Journal of Agricultural Food Chemistry 46: $361-367$.

DOI: https://doi.org/10.1021/jf970486b

15. Gupta M., Mazumder U.K., Kumar R.S., Gomathi P., Rajeshwar Y., Kakoti B.B. \& Selven V.T. (2005). Antiinflammatory, analgesic and antipyretic effects of methanol extract from Bauhinia racemosa stem bark in animal models. Journal of Ethnopharmacology 98: 267 - 273.

DOI: https://doi.org/10.1016/j.jep.2005.01.018

16. Gurib-Fakim A. (1991). Phytochemical screening of 38 Mauritian medicinal plants. Revue Agricole et Sucriere de Ille Maurice 69: 42 - 50.

17. Gülçin İ., Oktay M., Küfrevioğlu Ö.İ. \& Aslan A. (2002). Determination of antioxidant activity of lichen Cetraria islandica (L). Journal of Ethnopharmacology 79: 325 329.

18. Harborne J.B. \& Baxter H. (1999). The Handbook of Natural Flavonoids, volume 2, pp. IX-XV, 30, 36, 39, 381, 384, 476. John Wiley and Sons, New York, USA.

19. Ito N., Hirose M., Fukushima H., Tsuda T., Shirai T. \& Tatenatsu M. (1986). Studies on antioxidants: their carcinogenic and modifying effects on chemical carcinogens. Food and Chemical Toxicology 24: 1071 - 1092.

20. Jayprakash G.K., Singh R.P. \& Sakariah K.K. (2001). Antioxidant activity of grape seed extracts on peroxidation models in vitro. Food Chemistry 73: 285 - 290.

DOI: https://doi.org/10.1016/S0308-8146(00)00298-3

21. Kumaran A. \& Karunakaran R.J. (2007). In vitro antioxidant activities of methanol extracts of five Phyllanthus species from India. LWT- Food Science and Technology 40: $344-352$.

DOI: https://doi.org/10.1016/j.lwt.2005.09.011

22. Lee K.S., Lee S.J., Park H.J., Chung J.P., Han K.H. \& Chon C.Y. (2001). Oxidative stress effect on the activation of hepatic stellate cells. Journal of Medicine 42(1): $1-8$. DOI: https://doi.org/10.3349/ymj.2001.42.1.1

23. Lobo V., Patil A., Phatak A. \& Chandra N. (2010). Free radicals, antioxidants and functional foods: impact on human health. Pharmacognosy Review 4: 118 - 126. DOI: https://doi.org/10.4103/0973-7847.70902

24. Lompo M., Dubois J. \& Guissou I.P. (2007). In vitro preliminary study of free radical scavenging activity of extract from Khaya senegalensis A. Juss. (Meliaceae). Journal of Biological Sciences 7: $677-680$. DOI: https://doi.org/10.3923/jbs.2007.677.680

25. Loots D.T., Van Der Westhuizen F.H. \& Botes L. (2007). Aloe ferox leaf gel phytochemical content, antioxidant capacity, and possible health benefits. Journal of Agricultural Food Chemistry 55: 6891 - 6899. DOI: https://doi.org/10.1021/jf071110t

26. Madsen H.L. \& Bertelsen G. (1995). Spices as antioxidants. Trends in Food Science and Technology 6: 271 - 277.

27. Manaharan T., Appleton D., Cheng H.M. \& Palanisamy U.D. (2012). Flavonoids isolated from Syzygium aqueum leaf extract as potential antihyperglycemic agents. Food Chemistry 132: $1802-1807$. 
28. Manaharan T., Ming C.H. \& Palanisamy U.D. (2013). Syzygium aqueum leaf extract and its bioactive compounds enhances pre-adipocyte differentiation and 2-NBDG uptake in 3T3-L1 cells. Food Chemistry 15: $354-363$. DOI: https://doi.org/10.1016/j.foodchem.2011.11.147

29. Mario J., Simirgiotis S.A., Satoshi T., Hui Y., Kurt A.R., Margaret J.B., Roberto R.G., Bernard I.W. \& Edward J.K. (2008). Cytotoxic chalcones and antioxidants from the fruits of Syzygium samarangense (Wax Jambu). Food Chemsitry 107(2): $813-819$.

DOI: https://doi.org/10.1016/j.foodchem.2007.08.086

30. McCord Joe M. \& Fridovich I. (1969). Superoxide dismutase, an enzymic function for erythrocuprein (Hemocuprein). Journal of Biological Chemistry 244: $6049-6055$

31. Moneruzzaman K.M., Boyce A.N. \& Normaniza O. (2012). The Influence of hydrogen peroxide on the growth, development and quality of wax apple (Syzygium samarangense, var. jambu madu) fruits. Plant Physiology and Biochemistry 53: $101-110$.

DOI: https://doi.org/10.1016/j.plaphy.2012.01.016

32. Nakayama T., Yamaden M., Osawa T. \& Kawakishi S. (1993). Suppression of active oxygen-induced cytotoxicity by flavonoids. Biochemistry and Pharmacology 45: $265-267$.

33. Niehius W.G. \& Samuelson B. (1968). Formation of malondialdehyde from phospholipid arachidonate during microsomal lipid peroxidation. European Journal of Biochemistry 6: $126-130$.

DOI: https://doi.org/10.1111/j.1432-1033.1968.tb00428.x

34. Oyaizu M. (1986). Studies on product of browning reaction prepared from glucose amine. Japanese Journal of Nutrition 44(6): 307 - 315 .

DOI: https://doi.org/10.5264/eiyogakuzashi.44.307

35. Ozgen M., Schreerens J.C., Reese R.N. \& Miller R.A. (2010). Total phenolic, anthocyanidin contents and antioxidant capacity of selected elderberry (Sambucus canadensis L.) accession. Pharmacognosy Magazine 6(23): $198-203$.

DOI: https://doi.org/10.4103/0973-1296.66936

36. Palanisamy U., Ming C.H., Masilamani T., Subramaniam T., Teng L.L. \& Radhakrishnan A.K. (2008). Rind of rambutan, Nephelium lappaceum, a potential source of natural antioxidants. Food Chemistry 109: $54-63$.

DOI: https://doi.org/10.1016/j.foodchem.2007.12.018

37. Pataki T., Bak I., Kovacs P., Bagchi D., Dipak D.K. \&
Tosaki A. (2002). Grape seed proanthocyanidins improved cardiac recovery during reperfusion after ischemia in isolated rat hearts. American Journal of Clinical Nutrition 75: $894-899$.

38. Peter T., Padmavathi D., Sajini R.S. \& Sarala A. (2011). Syzygium samarangense: a review on morphology, phytochemistry and pharmacological aspects. Asian Journal of Biochemistry and Pharmaceutical Research 4: $155-163$.

39. Pietta P.G. (2000). Flavonoids as antioxidants. Journal of Natural Products 63(7): 1035 - 1042.

DOI: https://doi.org/10.1021/np9904509

40. Prieto P., Pineda M. \& Aguilar M. (1999). Spectrophotometric quantitation of antioxidant capacity through the formation of a phosphomolybdenum complex: specific application to the determination of vitamin E. Annals of Biochemistry 269(2): 337 - 341.

DOI: https://doi.org/10.1006/abio.1999.4019

41. Raga D.D., Cheng C.L., Lee K.C., Olazimana W.Z., De Guzmana V.J., Shen C.C., Franco Jr F.C. \& Ragasa C.Y. (2011). Bioactivities of triterpenes and a sterol from Syzygium samarangense. Zeitschrift für Naturforschung C 66: $235-244$.

DOI: https://doi.org/10.5560/ZNC.2011.66c0235

42. Reddy L.J. \& Jose B. (2011). Chemical composition and antibacterial activity of the volatile oil from the leaf of Syzygium Samarangense (Blume) Merr. \& L.M. Perry. Asian Journal of Biochemical and Pharmaceutical Research 3: $263-269$.

43. Shen S.C., Chang W.C. \& Chang C.L. (2012). Fraction from wax apple [Syzygium samarangense (Blume) Merrill and Perry] fruit extract ameliorates insulin resistance via modulating insulin signaling and inflammation pathway in tumor necrosis factor $\alpha$-treated FL83B mouse hepatocytes. International Journal of Molecular Science 13: $8562-$ 8577.

DOI: https://doi.org/10.3390/ijms13078562

44. Tanaka M., Kuie C.W., Nagashima Y. \& Taguchi T. (1988). Application of antioxidative maillard reaction products from histidine and glucose to sardine products. Nippon Suisan Gakkaishi 54: 1409 - 1414.

DOI: https://doi.org/10.2331/suisan.54.1409

45. Yeh C. \& Yen G. (2006). Induction of hepatic antioxidant enzymes by phenolic acids in rats is accompanied by increased levels of multidrug resistance- associated protein 3 mRNA expression. Journal of Nutrition 136: 11 - 15. 